\title{
Review
}

\section{Maggot Therapy: The Science and Implication for CAM Part I-History and Bacterial Resistance}

\author{
Yamni Nigam ${ }^{1}$, Alyson Bexfield ${ }^{1,2}$, Stephen Thomas $^{3}$ and Norman Arthur Ratcliffe ${ }^{2}$ \\ ${ }^{1}$ School of Health Science, University of Wales Swansea, Singleton Park, Swansea SA2 8PP, UK, \\ ${ }^{2}$ Department of Biological Sciences, University of Wales Swansea, Singleton Park, Swansea SA2 8PP, UK and \\ ${ }^{3}$ Biosurgical Research Unit (SMTL), Princess of Wales Hospital, Coity Road, Bridgend CF31 1RQ, UK
}

\begin{abstract}
It is now a universally acknowledged fact that maggot therapy can be used successfully to treat chronic, long-standing, infected wounds, which have previously failed to respond to conventional treatment. Such wounds are typically characterized by the presence of necrotic tissue, underlying infection and poor healing. Maggot therapy employs the use of freshly emerged, sterile larvae of the common greenbottle fly, Phaenicia (Lucilia) sericata, and is a form of artificially induced myiasis in a controlled clinical situation. In this review article, we will discuss the role of maggots and their preparation for clinical use. Maggot therapy has the following three core beneficial effects on a wound: debridement, disinfection and enhanced healing. In part I we explore our current understanding of the mechanisms underlying these effects.
\end{abstract}

Keywords: Maggot debridement therapy - MRSA - antimicrobial - Lucilia sericata - wounds

\section{Introduction I-The Rise and Fall of Maggot Therapy}

Numerous clinical reports have been published that describe the outstanding effects of maggot therapy, most notably on debridement, cleansing, disinfection and healing of indolent wounds, many of which have previously failed to respond to conventional treatment (1-11). Current day maggot therapy, with its multi-action approach to wound cleansing and healing, is highly successful.

Records of maggots in wounds, however, and the recognition of improvement in the wound state as a consequence of infestation, date back to the 16th century (12). In 1829, Baron Dominic Larrey, Napoleon's battlefield surgeon, described how men had arrived at his field hospital with healing maggot-infested wounds (13). The wounds were sustained in battle, but, owing to the presence of maggots, were not infected and showed accelerated healing. Such positive accounts were

For reprints and all correspondence: Yamni Nigam, University of Wales Swansea, Singleton Park, Swansea SA2 8PP, UK. E-mail:

Y.Nigam@swansea.ac.uk made by many surgeons who followed, but it was William Baer, Professor of Orthopaedic Surgery at the John Hopkins School of Medicine in Maryland, USA, who is believed to be the founder of modern maggot therapy (14).

It was Baer who pioneered the use of sterile maggots as a reputable method of wound therapy, following observations he made about the value of maggots in traumatic wounds on the battlefield in France during World War 1. Such was the success of Baer's work that by the mid-1930s almost 1000 North American surgeons employed maggot therapy (15) and by the end of the decade it was in use in over 300 hospitals in the US and Canada. However, by 1940, a new era was dawning. This era which saw the introduction and widespread use of antibiotics following the mass production of penicillin (16). So despite the obvious success of maggot therapy, by the mid-1940s it had practically disappeared from use. In Part 1 of this review, we introduce the stages involved in the wound healing process, the advantages in the use of maggots for the cleaning (debridement) of infected wounds, and the possible mechanisms underlying the debridement of wounds by maggots. The antimicrobial activity of maggots to treat methicillinresistant Staphylococcus aureus (MRSA)-infected wounds

(C) The Author (2006). Published by Oxford University Press. All rights reserved.

The online version of this article has been published under an open access model. Users are entitled to use, reproduce, disseminate, or display the open access version of this article for non-commercial purposes provided that: the original authorship is properly and fully attributed; the Journal and Oxford University Press are attributed as the original place of publication with the correct citation details given; if an article is subsequently reproduced or disseminated not in its entirety but only in part or as a derivative work this must be clearly indicated. For commercial re-use, please contact journals.permissions@ oxfordjournals.org 
is also described and details of the nature of the potent antibacterial activity of maggot secretions are then considered in Part II of this review.

\section{Review of Wounds and Events during Healing}

A wound is a breach in the skin, which may allow the entry of microorganisms, possibly leading to infection. Wound tissue provides the rich environment necessary for the proliferation of microbes. It is characterized by hypoxia, necrosis and often an accompanying impaired immune response owing to suboptimal delivery of immune effector molecules through damaged blood vessels (17). This compromised, necrotic, sloughy tissue provides a warm, moist and nutritive environment, perfect for replication of colonizing bacteria. Bacterial species which were previously harmless commensals of the human body, most commonly on the skin, may become pathogenic in a wound environment (18). In order for a wound to heal, it must progress through the following four main stages of the healing process (19): (i) the inflammatory phase where hemostasis occurs and numerous inflammatory mediators are released. Leukocytes migrate into the wound, and the bacterial burden of the wound is decreased. (ii) The destructive phase which sees the phagocytosis of necrotic tissue and killing of ingested microbes and foreign particles. Numerous growth factors are released during this phase. (iii) The proliferative phase involves the formation of new capillary loops and granulation tissue (angiogenesis), fibroplasia and the synthesis of new matrix and collagen. (iv) The maturation phase occurs when wound collagen is remodeled and reorganized. The wound contracts and epithelialization occurs. These events often happens during wound healing using adaptogens (20) (natural herb products that increase the body's resistance to physical, chemical or biological stresses). There is considerable overlap between the various stages, and the entire healing process can take months to complete, with full maturation often not achieved until a year after the wound was initiated.

\section{Types of Wounds}

Wounds can be broadly divided into two types, acute and chronic, which exhibit significant differences in the healing process. An acute wound is one which is usually instigated by a sudden, solitary insult, such as a traumatic injury. Such wounds generally proceed through the healing process in an orderly manner. In contrast, a chronic wound, such as a leg ulcer, is usually owing to an underlying pathological process, such as diabetes or vascular insufficiency, which produces a repeated and prolonged insult to the tissue, resulting in severe damage. The chronic wound does not normally progress through the healing process, often remaining in the inflammatory, infected phase and causing much discomfort and distress to the patient. Although maggots can be used for any kind of purulent, sloughy wound on the skin, independent of the underlying disease or the location on the body (21), it is in the cleansing and healing of such chronic wounds that maggot therapy becomes an invaluable tool.

\section{Maggot Therapy: Selection of the Flies}

Many dipteran species are capable of infesting living vertebrate hosts (a condition termed myiasis). Maggot therapy is essentially artificially induced myiasis, performed in a controlled environment by experienced medical practitioners. Myiasis-causing flies may be grouped into two categories as follows: obligate and facultative parasites. Obligate parasites require the ingestion of living tissue in order to complete their lifecycles (22). Larvae of obligate parasites can cause severe damage to healthy tissue and are therefore unsuitable for use in maggot therapy. Facultative parasites are able to parasitize living hosts if conditions are favorable, but more commonly develop on carrion and therefore have greater potential for therapeutic use.

Selection of a suitable fly species for use in maggot therapy is of paramount importance, determining both the safety and success of the treatment. It is imperative to select a species that feeds almost exclusively on necrotic tissue. William Baer chose the larvae of Phaenicia sericata, the common green-bottle, as the most appropriate species for this application and this is the species still used by practitioners today. Phaenicia larvae are facultative parasites, unable to ingest or significantly damage healthy human tissue (2). Infestations of living hosts by Phaenicia do, however, occur, most commonly in sheep to induce an often fatal condition known as sheep strike. Exactly why Phaenicia attack the healthy tissue of sheep and appear unable to do the same to human tissue is as yet unknown.

\section{Female Flies, Eggs, Larvae and Preparation for Clinical Use}

In the wild, adult female Phaenicia lay a large number of eggs (2000-3000) over the course of a few weeks, a necessity as relatively few will survive to adults. The eggs are laid in clusters directly onto the chosen food source, upon which the emerging larvae will feed. Larval development requires a moist environment to prevent desiccation, so larvae are generally found in nutritious, damp places such as decaying animal corpses or moist, necrotic wounds (22). Eggs hatch within 18-24 h, depending on optimal conditions, into first instar larvae (maggots), $\sim 1-2 \mathrm{~mm}$ in length, which immediately and actively begin to feed. It is this vigorous feeding activity, which is beneficial to an infected or necrotic wound. Maggots feed by the extracorporeal secretion of a wide spectrum of proteolytic enzymes that liquefy the host tissue (23-26). This semi-digested liquid material is then ingested as a source of nutrients. The maturing first instar larvae continue to feed for $~ 4-5$ days, molting twice as they increase in size to $\sim 8-10 \mathrm{~mm}$, at which point they stop feeding and leave the wound or corpse to search for a dry place in the ground where they pupate (25). Following metamorphosis, an adult fly emerges from the pupa. In preparation for clinical use, flies typically oviposit onto porcine liver, and the eggs are separated and chemically sterilized. Resultant $\left(\mathrm{L}_{1}\right)$ larvae are sterile 
upon emergence from the egg and undergo rigorous testing to ensure their microbiological status (3). Larvae are then maintained under aseptic conditions prior to wound application.

\section{Debridement (Wound Clearing)}

Maggot therapy has the following three core beneficial effects on a wound: debridement, disinfection and enhanced healing. Debridement is the removal of cellular debris and non-viable necrotic tissue from the wound bed. This is a first, essential step before healing can commence. Removal of necrotic tissue abolishes many of the associated bacteria and also reduces wound odor. The removal of necrotic tissue, which acts as a microbial substrate, may also reduce the risk of infection. During the inflammatory stage of wound healing host leucocytes play an important role in debridement of wound sites, degrading damaged extracellular matrix (ECM) components through the release of proteases. The injury is initially filled with a provisional wound matrix consisting predominantly of fibrin and fibronectin. Key proteases are involved in ECM degradation (see below). These are released from neutrophils, macrophages, fibroblasts, epithelial and endothelial cells. As healing proceeds, and new ECM constituents such as collagen, elastin and proteoglycans are synthesized, damaged ECM is removed by these proteases (27).

\section{Chronic Wounds}

Chronic wounds do not proceed through the normal healing process and are typically characterized by prolonged inflammation, inhibition of cell proliferation $(28,29)$, incomplete ECM remodeling and a failure to epithelialize (30). Over expression and inefficient debridement of temporary ECM components, e.g. fibronectin and fibrin, contribute to the failure of chronic wounds to heal. The entire environment of a chronic wound must be rebalanced for wound repair to proceed to completion, an undertaking which is unlikely to occur without extraneous intervention and one of the explanations as to why chronic wounds may persist for many years.

There are a number of existing methods for the debridement of chronic wounds as described by Schultz et al. (27). These include surgical and sharp debridement (using scalpel or scissors to remove debris and necrotic tissue), mechanical debridement using methods such as wet-to-dry dressings, wound irrigation and whirlpool techniques, enzymatic debridement using the application of exogenous enzymes, and autolytic debridement using hydrogels and hydrocolloids. Each of these techniques has associated disadvantages such as extended treatment times, pain and mechanical damage to underlying healthy tissue.

\section{Maggot Debridement Therapy}

The alternative is maggot therapy. Maggots debride wounds quickly and effectively, without damage to viable tissue. Maggots are photophobic and will naturally move into the deep crevices that may be beyond the reach of a surgeon's scalpel. Reports have been published marveling at the benefits of maggot debridement therapy (MDT) in all sorts of wounds, including abscesses, burns, gangrenous wounds, arterial and venous ulcers, osteomyelitis, diabetic foot ulcers and pressure sores (7,9,31-33). One such study compared MDT with conservative debridement therapy for the treatment of pressure sores (34). Here, $80 \%$ of maggot-treated wounds $(n=43)$ were completely debrided, while only $48 \%$ of conventionally treated wounds $(n=49)$ were completely debrided. Also, by using maggots, total wound surface area decreased, whereas during conventional debridement therapy, the total wound area had increased $(p=0.001)$ (34). The report concluded that maggot therapy was a more effective and efficient way of debriding chronic pressure sores than the conventional treatments prescribed.

\section{Mechanisms of MDT}

How exactly maggots remove devitalized, necrotic tissue from the wound is currently actively being investigated. Research into the debridement mechanisms underlying maggot therapy has revealed that maggots secrete a rich soup of digestive enzymes while feeding, including carboxypeptidases A and B (35), leucine aminopeptidase (35), collagenase $(23,36)$ and serine proteases (trypsin-like and chymotrypsin-like enzymes) (35,37). Recently, workers in Nottingham, UK, demonstrated in vitro a range of enzymes secreted by $P$. sericata larvae (26). Four proteolytic enzymes, comprising two serine proteases, a metalloproteinase and an aspartyl proteinase, were detected, with molecular weights ranging from 20 to $40 \mathrm{kDa}$, with activity across a wide $\mathrm{pH}$ range. A chymotrypsin-like serine proteinase exhibited excellent degradation of ECM components laminin, fibronectin, and collagen types I and III (26), and may therefore play a significant role in the digestion of wound matrix and effective debridement.

The mechanical action of numerous wriggling maggots in a necrotic debris-filled wound has also been suggested in aiding wound debridement. Maggots possess a pair of mandibles (hooks) which assist with locomotion and attachment to tissue. This probing and maceration of wound tissue with maggot mouthhooks may enhance debridement (38), but these hooks are used during feeding to disrupt membranes and thus facilitate the penetration of proteolytic enzymes (3). Together, this mechanical action and the secretion of powerful, proteolytic enzymes may be the secret of efficient tissue debridement.

\section{Disinfection (Introduction to Antibiotic Activity)}

For wounds to heal, and progress through stages of destruction and proliferation onto maturation, infection needs to be eliminated. The majority of wounds are polymicrobial, hosting a range of both anaerobic and aerobic bacteria $(18,39)$. Antimicrobial treatment of clinically infected and non-healing wounds, should, therefore, encompass broad-spectrum anti- 


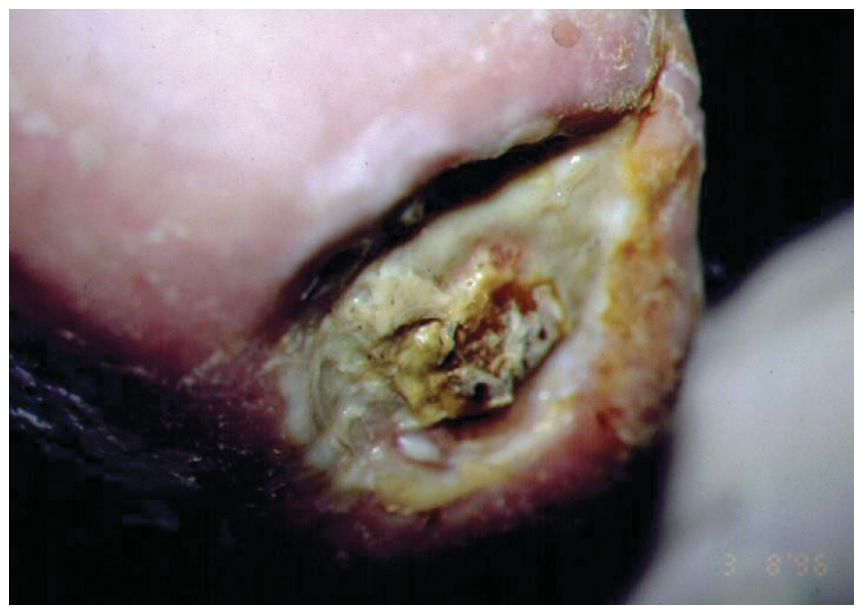

Figure 1. Wound before maggot debridement therapy. This wound, covered with a thick layer of slough, failed to respond to conventional treatment over 18 months.

microbials in order to cleanse the wound effectively. The application of maggots to an infected wound results in the rapid elimination of such infecting microorganisms $(2,6,40,41)$. The most frequently isolated pathogen from acute and chronic wounds is Staphylococcus aureus. S. aureus is carried innocuously by $\sim 30 \%$ of the general population (42) [40-70\% of hospital staff $(43,44)]$, usually on the moist skin in the nose, axillae (armpits) and perineum (groin), but can become pathogenic when able to enter damaged skin. S. aureus has caused great concern owing to its ability to acquire resistance to a range of antimicrobials.

\section{Penicillin Methicillin Resistance and MRSA}

In 1948, 4 years after the widespread introduction of penicillin, over $50 \%$ of nosocomial $S$. aureus were penicillin-resistant (45) owing to the production of penicillinase ( $\beta$-lactamase), an enzyme which inactivates $\beta$-lactam antibiotics (46). Currently, the majority (80-90\%) of S. aureus are penicillinresistant. In 1960, a structural modification of penicillin saw the synthetic production of methicillin, which was active against penicillin-resistant strains of $S$. aureus. The launch of methicillin, however, failed to control the proliferation of resistant strains of bacteria and the first clinical isolate of MRSA was reported in 1961 (47). Since then, MRSA has continued to disseminate rapidly, causing serious hospital and community infections all over the world, with global increases in both the numbers of infected patients and mortality. The recent isolation of vancomycin-resistant strains of $S$. aureus (VRSA) in Japan (48) severely reduces the repetoire of drugs available to treat infections caused by resistant strains of S. aureus.

In the literature, there is an ever increasing trend supporting the clinical use of maggots for treating wounds infected with MRSA $(6,40,49,50)$. This support, initially anecdotal, was strengthened by case studies and most recently, strong laboratory evidence indicates that maggots do possess the ability to

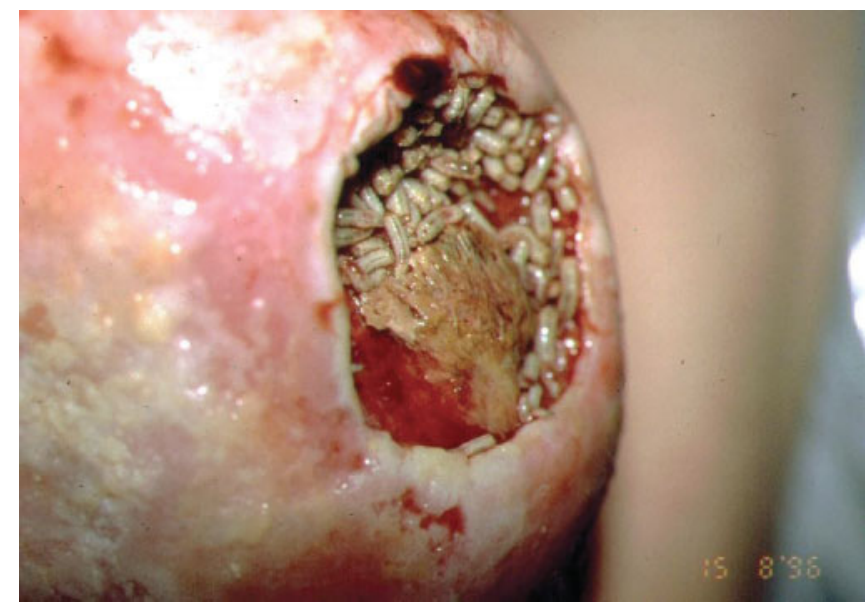

Figure 2. Wound following three applications of maggots. The wound is completely free of slough and rich with granulation tissue.

kill clinical isolates of MRSA (51,52). As an example, Fig. 1 shows a wound $5 \mathrm{~cm}$ in diameter and totally covered with a thick layer of viscous slough. One pot of larvae was applied and left for $48 \mathrm{~h}$, after which there was an immediate and marked improvement to the wound. Two further applications of larvae were made. At this point, only 6 days after maggot therapy had commenced, the wound, which had not responded to conventional treatment over 18 months, was now completely free from slough. It was filling rapidly with healthy granulation tissue and a swab failed to detect any presence of MRSA (Fig. 2). Larval therapy was now discontinued and the wound continued to progress normally and healed uneventfully (6).

\section{Acknowledgments}

We wish to thank Bro Morgannwg and Action Medical Research (grant number AP1010) for financial support. The work was partly funded by the Bro Morgannwg NHS Trust.

\section{References}

1. Baer WS. The treatment of chronic osteomyelitis with the maggot (larva of the blow fly). J Bone Joint Surg 1931;13:438-75.

2. Weil GC, Simon RJ, Sweadner WR. A biological bacteriological and clinical study of larval or maggot therapy in the treatment of acute and chronic pyogenic infections. Am J Surg 1933;19:36-48.

3. Thomas S, Jones M, Shutler S, Jones S. Using larvae in modern wound management. J Wound Care 1996;5:60-9.

4. Johnson S. Larval therapy in the treatment of wounds: case history. Br J Community Nurs 1999;4:293-5.

5. Mumcuoglu KY, Ingber A, Gilead L, Stessman J, Friedman R, Schulman H, et al. Maggot therapy for the treatment of intractable wounds. Int J Dermatol 1999;38:623-7.

6. Thomas S, Jones M. Maggots can benefit patients with MRSA. Pract Nurse 2000;20:101-4.

7. Graninger M, Grassberger M, Galehr E, Huemer F, Gruschina E, Minar E, et al. Biosurgical debridement facilitates healing of chronic skin ulcers. Arch Int Med 2002;162:1906-7.

8. Jukema GN, Menon AG, Bernards AT, Steenvoorde P, Taheri Rastegar A, Van Dissel JT. Amputation-sparing treatment by nature: "surgical" maggots revisited. Clin Infect Dis 2002;35:1566-71. 
9. Wollina U, Liebold K, Schmidt W-D, Hartmann M, Fassler D. Biosurgery supports granulation and debridement in chronic wounds-clinical data and remittance spectroscopy measurement. Int J Dermatol 2002;41: 635-9.

10. Sherman RA. Maggot therapy for treating diabetic foot ulcers unresponsive to conventional therapy. Diabetes Care 2003;26:446-51.

11. Sherman RA, Shimoda KJ. Presurgical maggot debridement of soft tissue wounds is associated with decreased rates of postoperative infection. Clin Infect Dis 2004;39:1067-70.

12. Goldstein H. Maggots in the treatment of wound and bone infections. J Bone Joint Surg 1931;13:476-8.

13. Larrey DJ. Observations on Wounds and Their Complications by Erysipelas Gangrene and Tetanus etc51-52 Paris: Clin. Chir. Transl. EF Rivinus, 1932. p. 34. Philadelphia: Key Mielke \& Biddle.

14. Sherman RA, Hall MJR, Thomas S. Medicinal maggots: an ancient remedy for some contemporary afflictions. Anпи Rev Entomol 2000;45: $55-81$.

15. Robinson W. Stimulation of healing in non-healing wounds by allantoin in maggot secretions and of wide biological distribution. J Bone Joint Surg 1935; 17:267-71

16. Chain E, Florey HW, Gardner AD, Heatley HG, Jenning MA, Orr-Ewing J, et al. Penicillin as a chemotherapeutic agent. Lancet 1940;2:226-8.

17. Waldrop J, Doughty D. In: Bryant R (ed). Wound-healing Physiology. Acute and Chronic Wounds. Nursing Management. London: Mosby Inc., 2000, 17-39.

18. Bowler P. The anaerobic and aerobic microbiology of wounds: a review. Wounds 1998;10:170-8.

19. Torrance C. The physiology of wound healing. Wound care in accident and emergency supplement. Nursing 1985;2:1-3.

20. Olalde JA, Margarici M, Amendola F, Del Castillo O. The systemic theory of livivng systems. Part IV: Systemic medicine-the praxis. Evid Based Complement Alternat Med 2005;2:429-39.

21. Mumcuoglu KY. Clinical applications for maggots in wound care. Am J Derm 2001;2:219-27.

22. Erzinclioglu Z. The biology of blowflies. Naturalist's Handbook 23: Blowflies Slough. England: Richmond Publishing Co. Ltd, 1996.

23. Ziffren SE, Heist HE, May SC, Womack NA. The secretion of collagenase by maggots and its implication. Ann Surg 1953;138:932-4.

24. Terra WR, Ferreira C. Insect digestive enzymes: properties compartmentalization and function. Comp Biochem Physiol 1994;109B:1-62.

25. Sherman RA. Maggot debridement in modern medicine. Infect Med 1998;15:651-6.

26. Chambers L, Woodrow S, Brown AP, Harris PD, Philips D, Hall M, et al. Degradation of extracellular matrix componets by defined proteinases from the greenbottle larva Lucilia sericata used for the clinical debridement of non-healing wounds. Br J Dermatol 2003;148:14-23.

27. Schultz GS, Sibbald RG, Falanga V, Ayello EA, Dowsett C, Harding K, et al. Wound bed preparation: a systematic approach to wound management. Wound Repair Regen 2003;11:1-28.

28. Bucalo B, Eaglstein WH, Falanga V. Inhibition of cell proliferation by chronic wound fluid. Wound Repair Regen 1993;1:181-6.

29. Agren MS, Steenfos HH, Dabelsteen S, Hansen JB, Dabelsteen E. Proliferation and mitogenic response to PDGF-BB of fibroblasts isolated from chronic leg ulcers is ulcer-dependent. J Invest Dermatol 1999;112:463-9.

30. Tarnuzzer RW, Shultz GS. Biochemical analysis of acute and chronic wound environments. Wound Repair Regen 1996;4:321-5.
31. Sherman RA, Tran JM-T, Sullivan R. Maggot therapy for venous stasis ulcers. Arch Dermatol 1996;132:254-6.

32. Mumcuoglu KY, Lipo M, Ioffe-Uspensky I, Miller J, Galun R. Maggot therapy for gangrene and osteomyelitis. Harefuah 1997;132:323-5.

33. Namias N, Varela JE, Varas RP, Quintana O, Ward CG. Biodebridement: a case report of maggot therapy for limb salvage after forth degree burns. J Burn Care Rehabil 2000;21:254-7.

34. Sherman RA. Maggot versus conservative debridement therapy for the treatment of pressure ulcers. Wound Repair Regen 2002;10:208-14.

35. Vistnes L, Lee R, Ksander A. Proteolytic activity of blowfly larvae secretions in experimental burns. Surgery 1981;90:835-41.

36. Hobson RP. Studies on the nutrition of blow-fly larvae. I. Structure and function of the alimentary tract. J Exp Biol 1931;8:110-23.

37. Casu RE, Pearson RD, Jarmey JM, Cadogan LC, Riding GA, Tellam RL. Extretory/secretory chymotrypsin from Lucilia cuprina: purification enzymatic specificity and amino avid sequence deduced from mRNA. Insect Mol Biol 1994;3:201-11.

38. Barnard DR. Skeletal-muscular mechanisms of the larva of Lucilia sericata (Meigen) in relation to feeding habit. Pan-Pac Entomol 1977;53:223-9.

39. Bowler P, Davies BJ. The microbiology of acute and chronic wounds. Wounds 1999;11:72-8.

40. Courtenay M. The use of larval therapy in wound management in the UK. J Wound Care 1999;8:177-9.

41. Hinshaw J. Larval therapy: a review of clinical human and veterinary studies. Available at: www.worldwidewounds.com/2000/oct/ janet-hinshaw/larval-therapy-human-and-veterinary.html.

42. Casewell MW, Hill RL. The carrier state: methicillin-resistant Staphylococcus aureus. J Antimicrob Chemother 1986;18(Suppl A):1-12.

43. Williams RE. Healthy carriage of Staphylococcus aureus: its prevalence and importance. Bacteriol Rev 1963;27:56-71.

44. Parnaby RM, O'Dwyer G, Monsey HA, Shafi MS. Carriage of Staphylococcus aureus in the elderly. J Hosp Infect 1995;33:201-6.

45. Barber M, Rozwadowska-Dowzenko M. Infection by penicillin-resistant staphylococci. Lancet 1948;ii:641-4.

46. Livermore DM. Antibiotic resistance in staphylococci. Int J Antimicrob Agents 2000;16:S3-10.

47. Jevons MP. Celbenin-resistant staphylococci. Br Med J 1961;1:124-5.

48. Hiramatsu K, Hanaki H, Ino T, Yabuta K, Oguzi T, Tenover FC. Methicillin-resistant Staphylococcus aureus clinical strain with reduced vancomycin susceptibility. J Antimicrob Chemother 1997;40:135-6.

49. Dissemond J, Kopperman M, Esser S, Schultewolter T, Goos M, Wagner SN. Treatment of methicillin-resistant Staphyloccus of a chronic leg ulcer. Hautarzt 2002;53:608-12.

50. Beasley WD, Hirst G. Making a meal of MRSA - the role of biosurgery in hospital-acquired infection. J Hosp Infect 2004;56:6-9.

51. Thomas S, Andrews A, Hay P, Bourgoise S. The anti-microbial activity of maggot secretions: results of a preliminary study. J Tissue Viability 1999;9:127-32.

52. Bexfield A, Nigam Y, Thomas S, Ratcliffe NA. Detection and partial characterisation of two antibacterial factors from the excretions/secretions of the medicinal maggot Lucilia sericata and their activity against methicillin-resistant Staphylococcus aureus (MRSA). Microbes Infect 2004;6:1297-304.

Received September 13, 2005; accepted March 23, 2006 


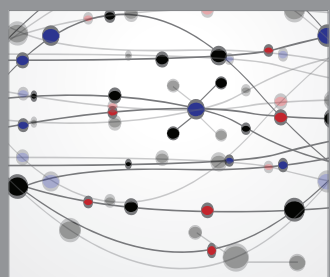

The Scientific World Journal
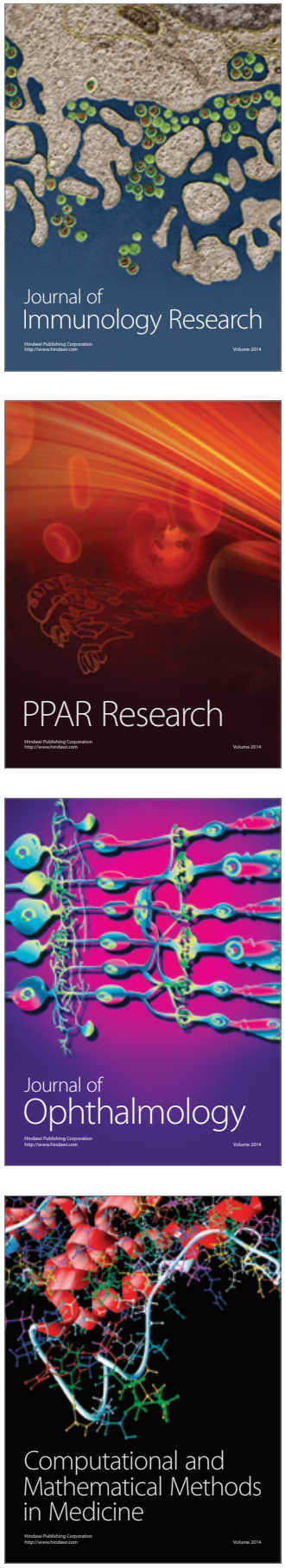

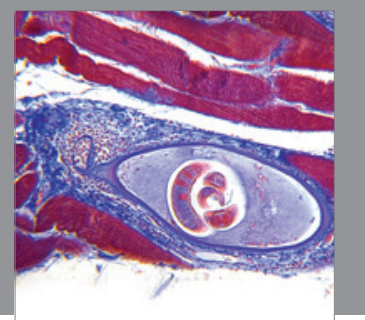

Gastroenterology

Research and Practice
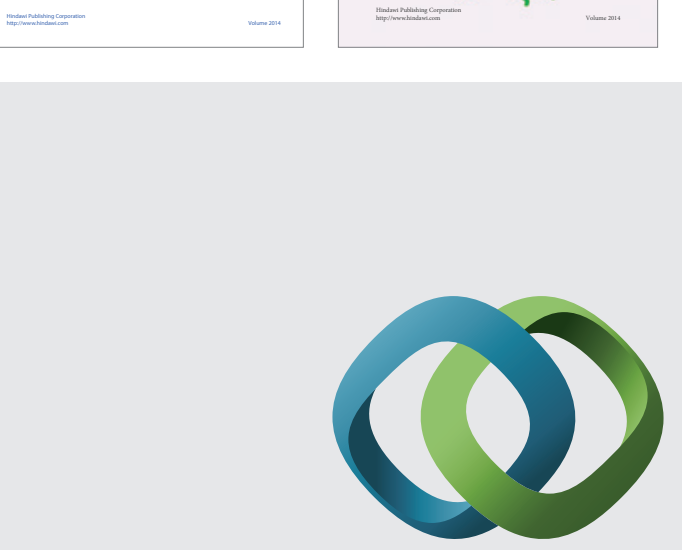

\section{Hindawi}

Submit your manuscripts at

http://www.hindawi.com
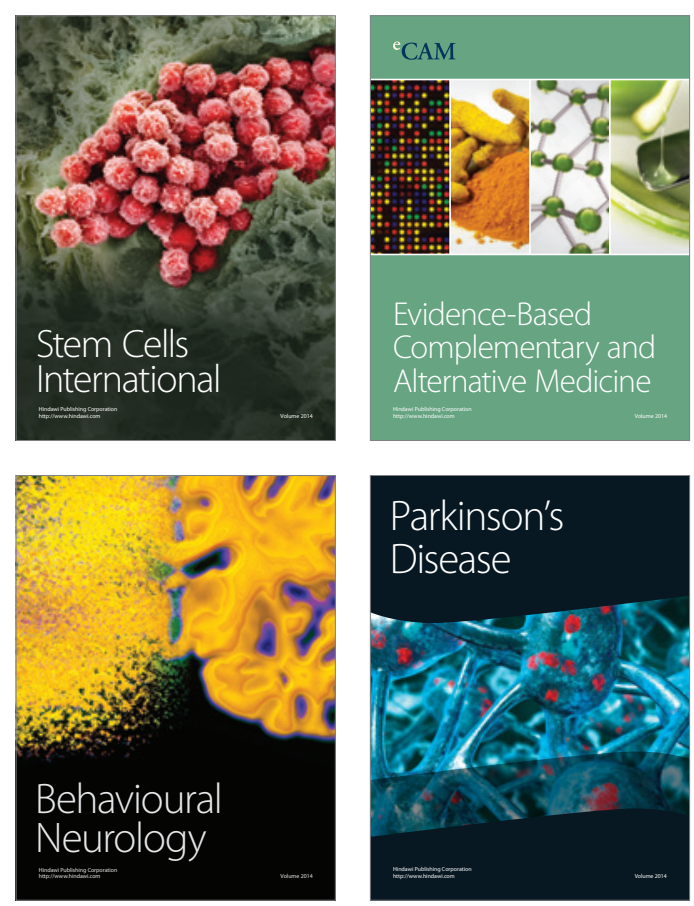

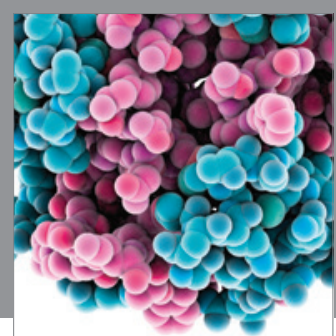

Journal of
Diabetes Research

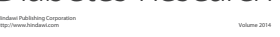

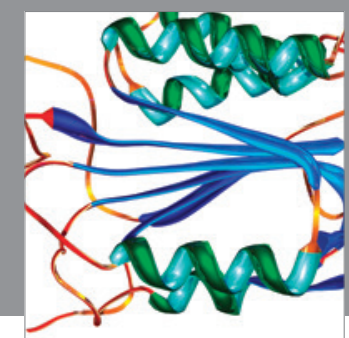

Disease Markers
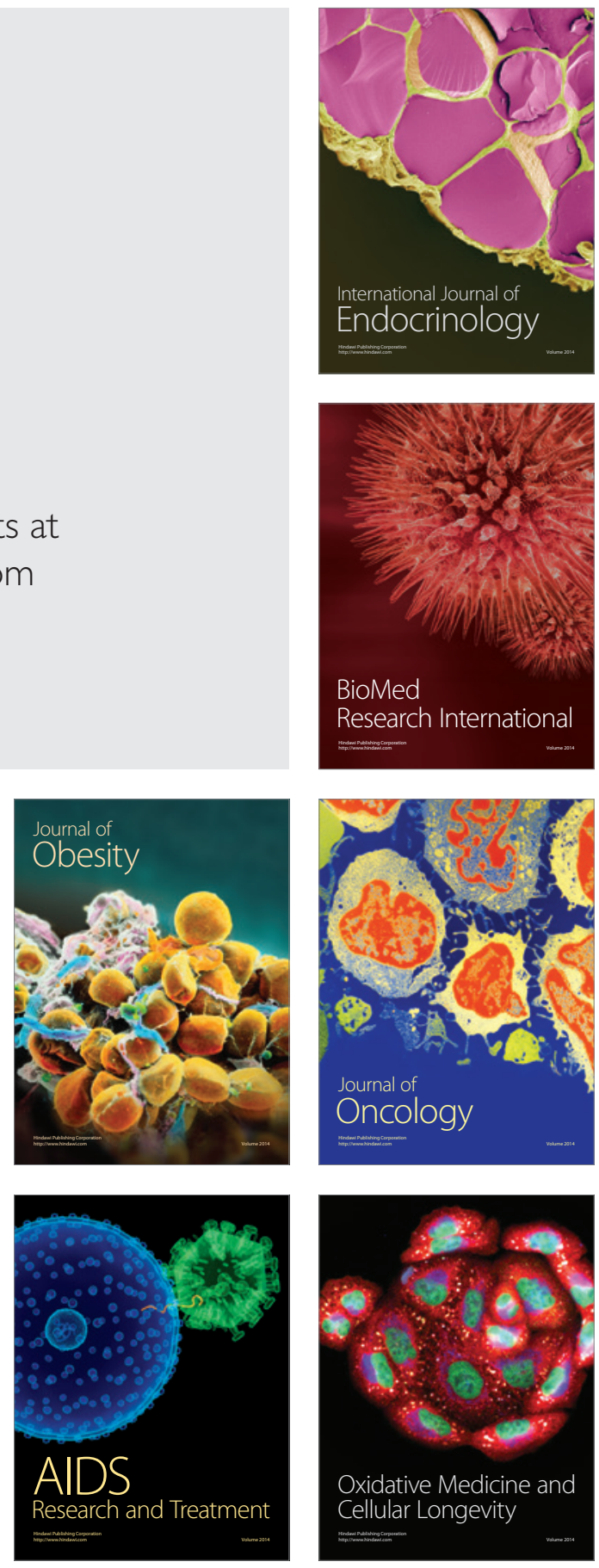